\title{
Design of Lubricant-infused Surfaces Based on Mussel-inspired Nanosilica Coatings: Solve Adhesion by pre-Adhesion
}

Rishun $\mathrm{Li}^{\mathrm{a}}$, Lizhi Zhao ${ }^{\mathrm{a}}$, Anfeng $\mathrm{Yao}^{\mathrm{a}}$, Didi $\mathrm{Si}^{\mathrm{a}}$, Yanlong Shang ${ }^{\mathrm{a}}$, Xiaoli Ding ${ }^{\mathrm{a}}$, Huiqin An ${ }^{\mathrm{b}}$, Hui Yea, Yuzhong Zhang ${ }^{\mathrm{a} *}$, Hong $\mathrm{Li}^{\mathrm{a}}$

a State Key Laboratory of Separation Membranes and Membrane Processes, School of Materials Science and Engineering, Tiangong University, Tianjin 300387, PR China

b School of Chemistry, Tiangong University, Tianjin 300387, PR China

* Corresponding Author:

Lizhi Zhao, Email: zhaolizhi_phd@163.com,

Yuzhong Zhang, Email: zhangyz2004cn@163.com

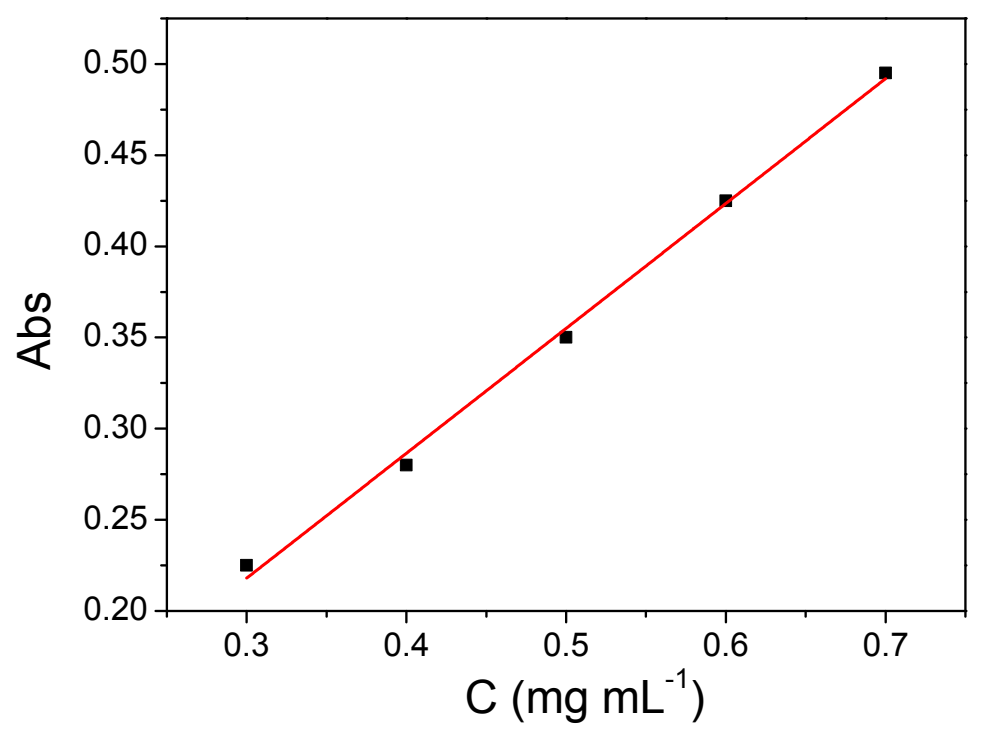

Figure S1. Standard curve of BSA based on the absorbance at $280 \mathrm{~nm}$ in PBS solution (pH 7.4). 

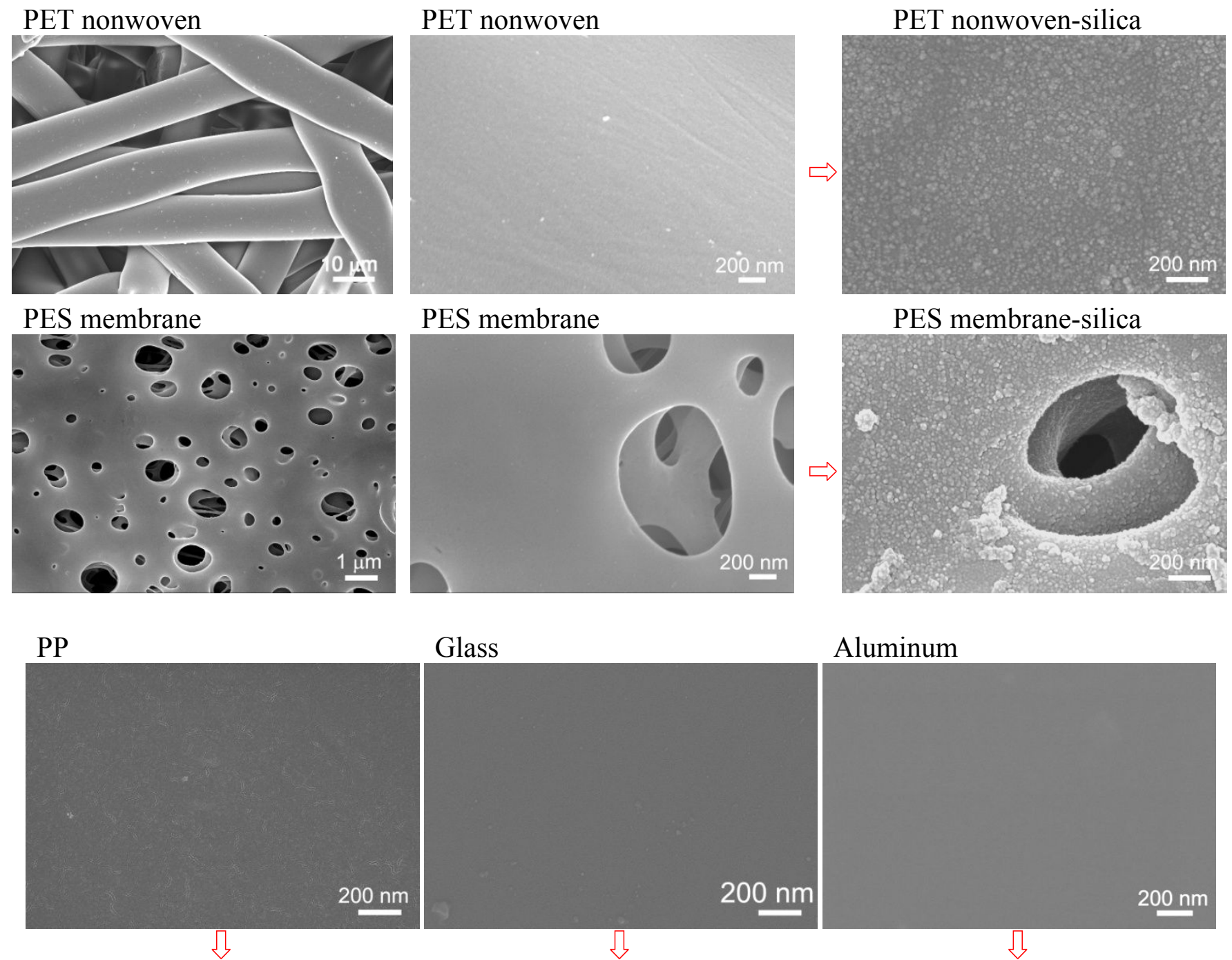

Glass

Aluminum

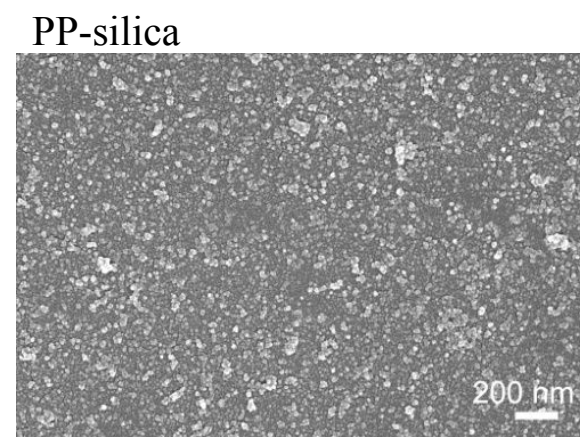

Glass-silica

Aluminum-silica
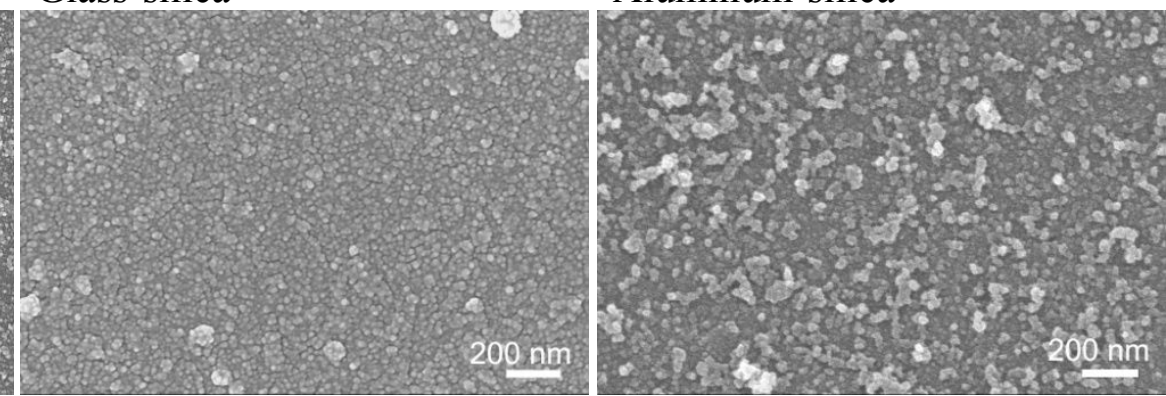

Figure S2. FESEM images of original PET nonwoven, PES membrane, PP, glass and aluminum substrates and after PDA-assisted silica coating. 


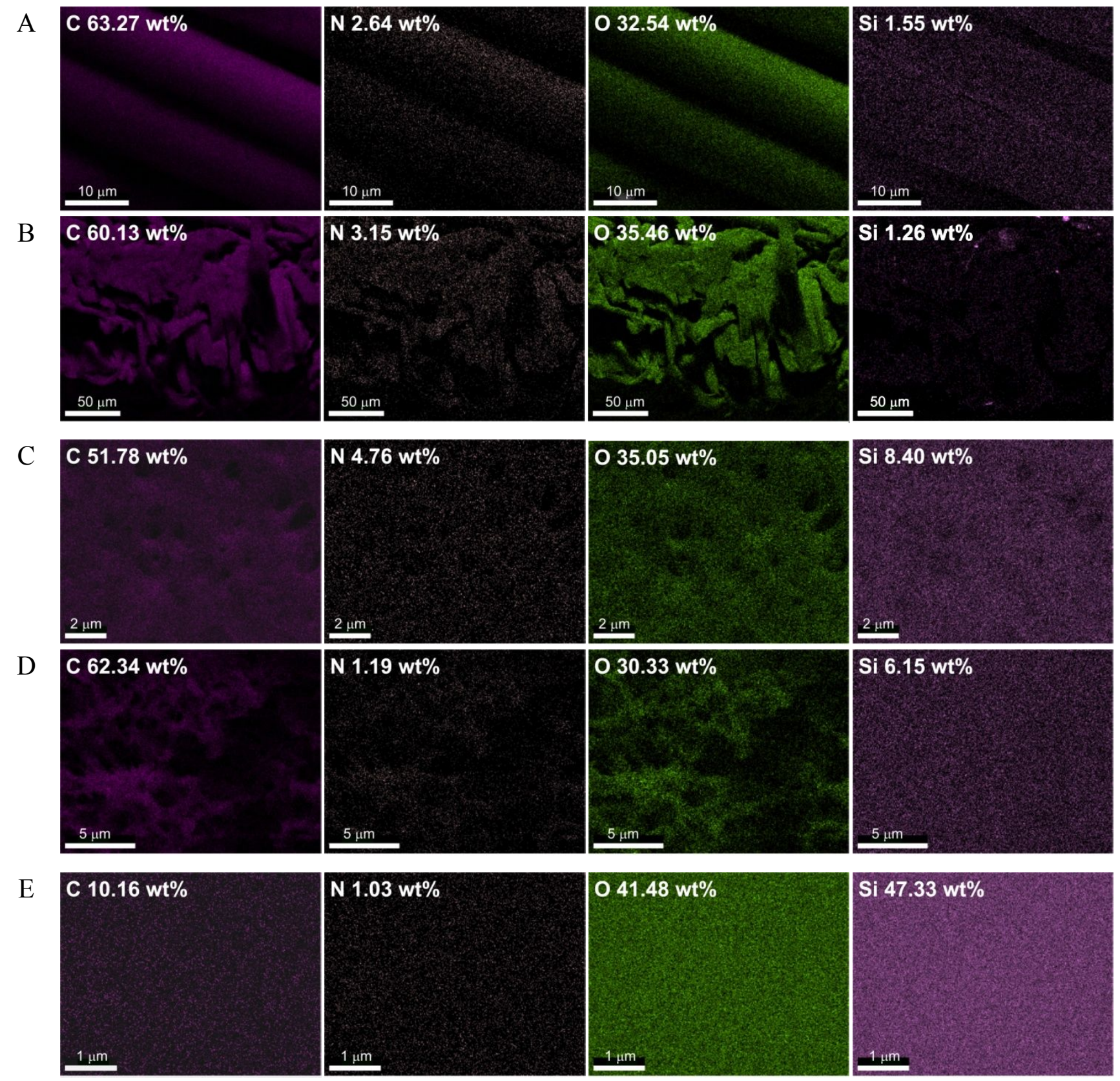

Figure S3. EDS mapping images of substrates after PDA-assisted silica coating. (A) surface of PET nonwoven; (B) cross-section of PET nonwoven; (C) surface of PES membrane; (D) cross-section of PES membrane; (E) surface of glass.

In the EDS mapping images of Figure S3, porous polymer substrates (nonwoven fabric and PES membrane) and non porous inorganic substrate (glass slides) are taken as examples, not all substrates are listed. 

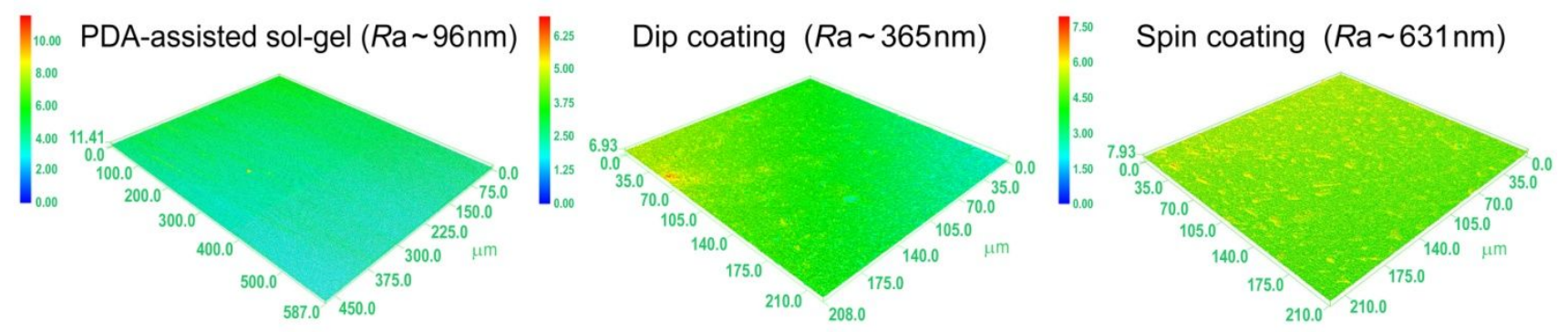

Figure S4. CSM images of PET track-etched membranes coated with nanosilica by PDA-assisted sol-gel process, dip coating and spin coating. Here the roughness measurements by AFM failed as the roughness of partial position may exceed the range $(>3 \mathrm{~nm}$ and $<1 \mu \mathrm{m})$ that AFM can measure, so the results were obtained by CSM instead.

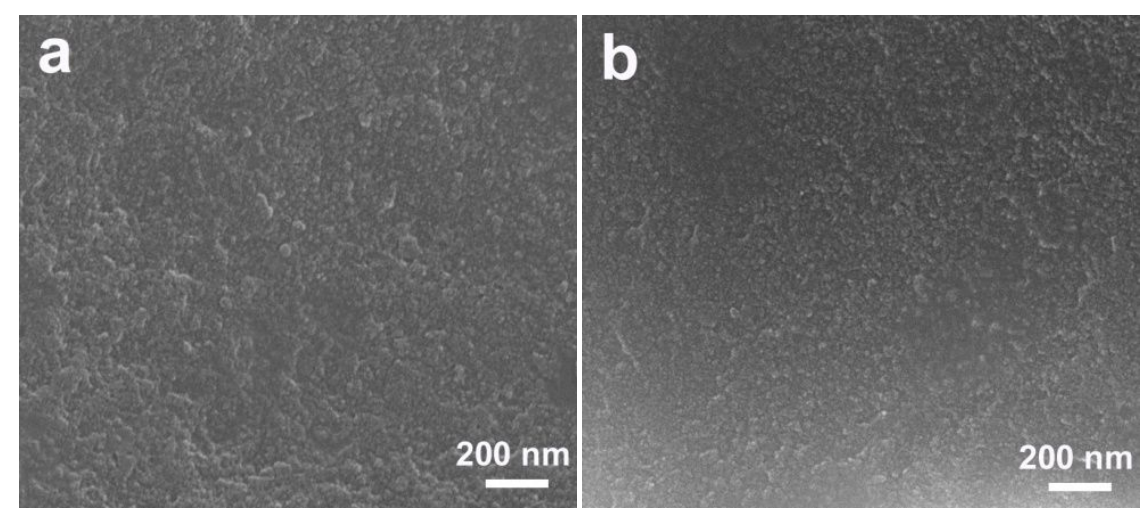

Figure S5. FESEM images of the PDA-mediated nanosilica coating on PET track-etched membrane (PET-silica) before (a) and after (b) ultrasonic treatment.
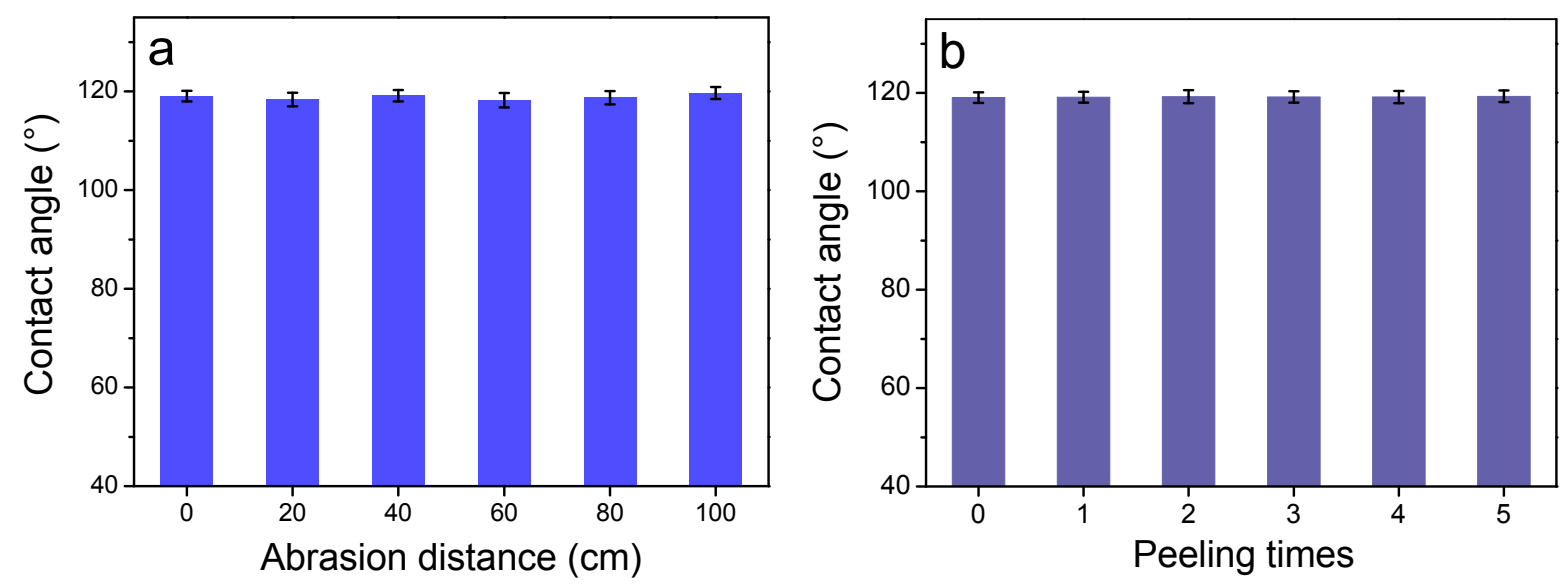

Figure S6. Contact angle changes of the fluorinated PDA-mediated nanosilica coating on PET track-etched membrane (PET-fluorination) when undergoing increasing abrasion distance (a) and tape peeling times. 

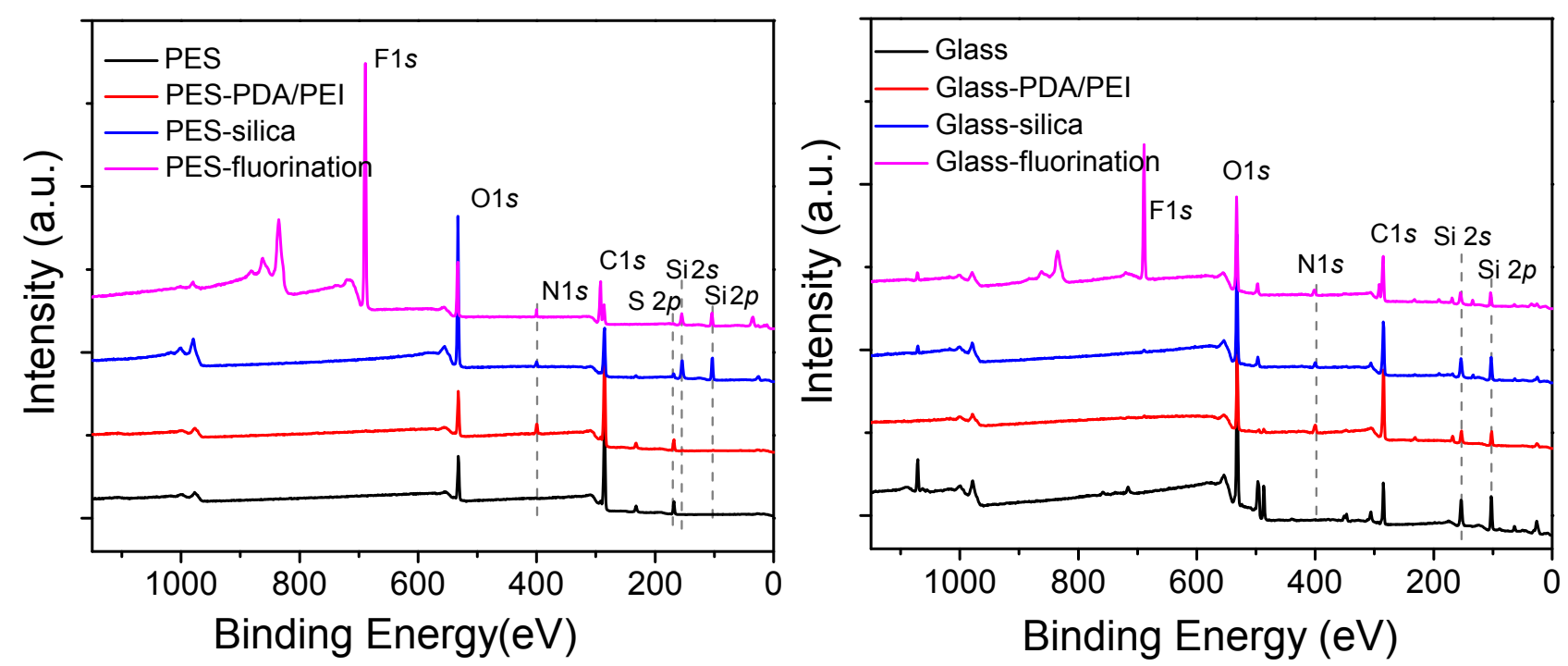

Figure S7. XPS spectra of original substrates, substrates-PDA/PEI (substrates deposited with PDA/PEI), substrates-silica (substrates-PDA/PEI coated with nanosilica) and substrate-PDA/PEI (fluorinated substrates-silica). Here porous material (PES membrane) and dense inorganic material (glass) were used as the substrate for example.

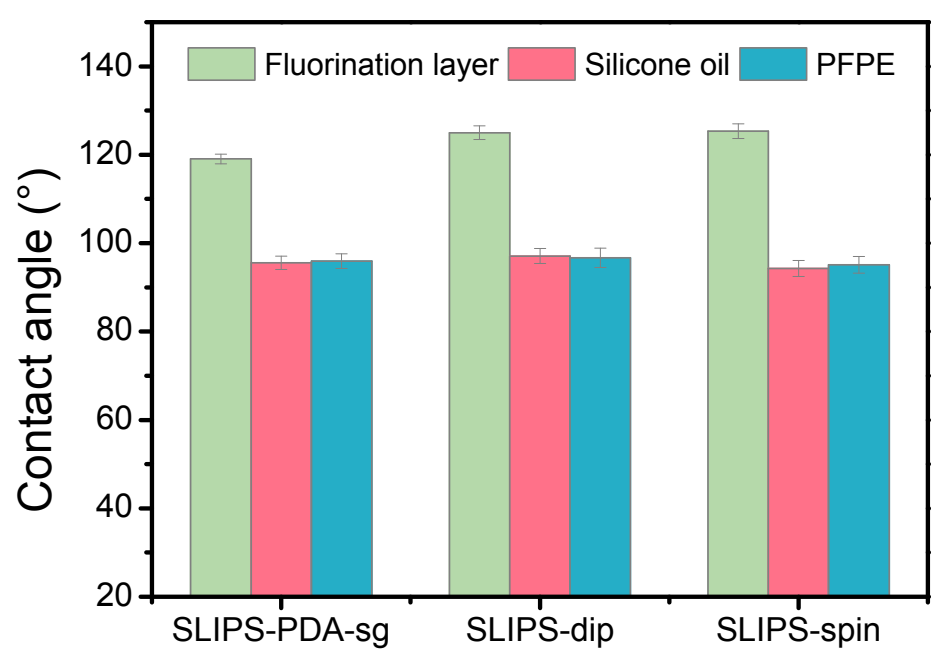

Figure S8. Contact angles of water on fluorination, silicone oil and PFPE layer of SLIPS-PDA-sg, SLIPS-dip and SLIPS-spin (the substrate is PET track-etched membrane). 


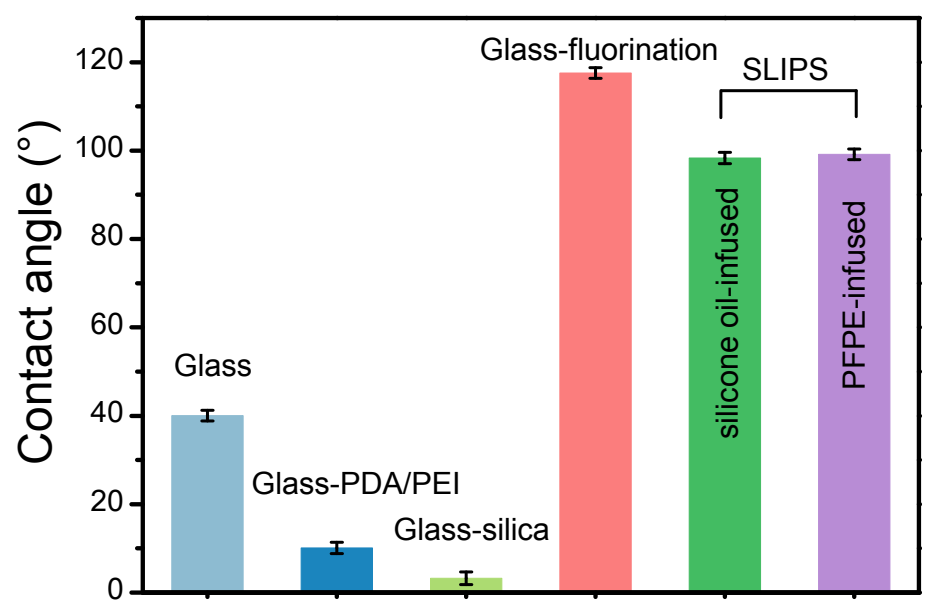

Figure S9. Contact angles of water on glass slide at various stages of surface modification and on silicone oil-infused and PFPE-infused glass.

Table S1. Surface/interface tensions of lubricants and water, and their contact angles on the fluorinated surfaces.

\begin{tabular}{cccccccccc}
\hline & $\gamma_{\mathrm{B}}$ & $\gamma_{\mathrm{A}}$ & $\gamma_{\mathrm{AB}}$ & $\theta_{\mathrm{B}}$ & $\theta_{\mathrm{A}}$ & $\theta$ & $R$ & $\Delta E_{1}$ & $\Delta E_{2}$ \\
Substrate-lubricant & $(\mathrm{mN} / \mathrm{m})$ & $(\mathrm{mN} / \mathrm{m})$ & $(\mathrm{mN} / \mathrm{m})$ & $\left(^{\circ}\right)$ & $\left(^{\circ}\right)$ & $\left({ }^{\circ}\right)$ & & $(\mathrm{mN} / \mathrm{m})$ & $(\mathrm{mN} / \mathrm{m})$ \\
\hline PET-PFPE & 17.0 & 72.8 & 56.1 & $\sim 0$ & 119 & 96 & 4.72 & 190.87 & 302.67 \\
PET-Silicone oil & 20.7 & 72.8 & 24.2 & $\sim 0$ & 119 & 96 & 5.01 & 256.70 & 333.00 \\
PES-PFPE & 17.0 & 72.8 & 56.1 & $\sim 0$ & 130 & 96 & 6.15 & 336.3 & 448.80 \\
PP-PFPE & 17.0 & 72.8 & 56.1 & $\sim 0$ & 115 & 98 & 2.73 & 72.96 & 184.76 \\
Glass-PFPE & 17.0 & 72.8 & 56.1 & $\sim 0$ & 110 & 99 & 2.18 & 35.34 & 147.14 \\
Aluminum-PFPE & 17.0 & 72.8 & 56.1 & $\sim 0$ & 136 & 100 & 4.04 & 263.50 & 361.09 \\
Fiber-PFPE & 17.0 & 72.8 & 56.1 & $\sim 0$ & 136 & 100 & 4.19 & 234.94 & 346.84 \\
Wood-PFPE & 17.0 & 72.8 & 56.1 & $\sim 0$ & 122 & 98 & 3.62 & 145.89 & 257.69 \\
\hline
\end{tabular}

Note: $\gamma_{\mathrm{A}}$ and $\gamma_{\mathrm{B}}$ are the surface tensions for the test liquid (water) to be repelled and the lubricant, $\gamma_{\mathrm{AB}}$ is the interfacial tension between the water and oil. $\theta_{\mathrm{A}}$ and $\theta_{\mathrm{B}}$ are the equilibrium CAs of water and lubricant on a flat solid surface; $R$ refers to roughness factor of the material, $R=\cos \theta_{\mathrm{A}} / \cos \theta$. 


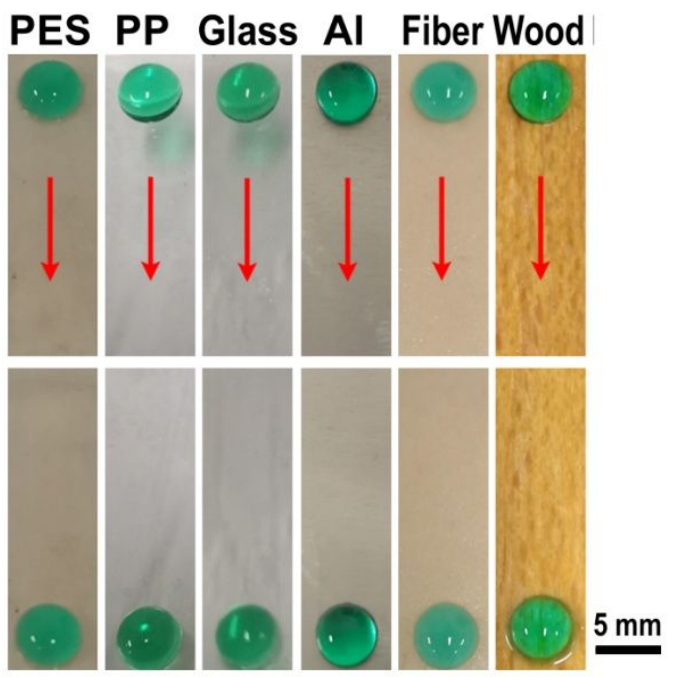

Figure S10. Images of bromocresol green (BCG) solution drop $(20 \mu \mathrm{L})$ sliding down on the PDA-mediated SLIPS prepared on different solid substrates.
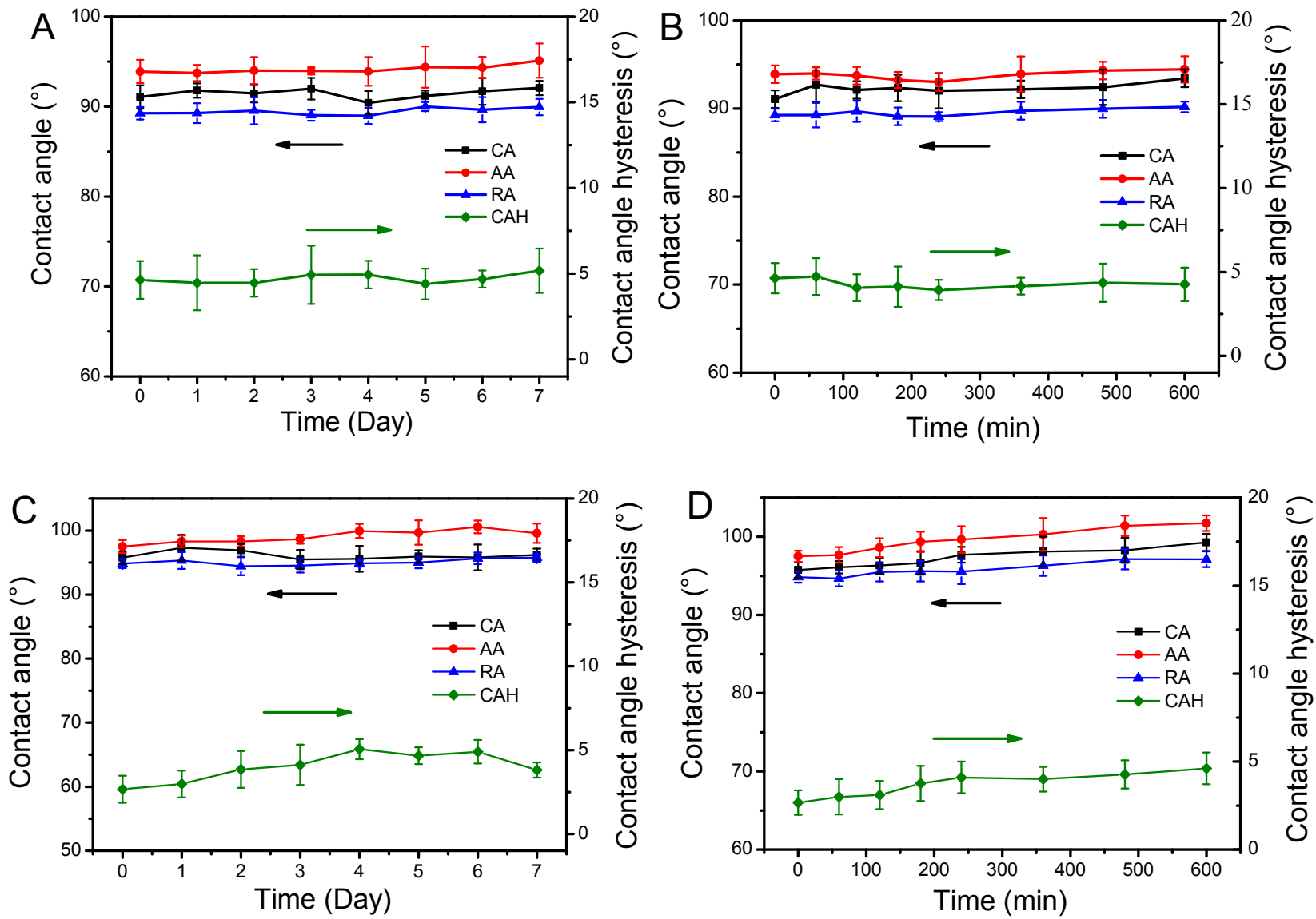

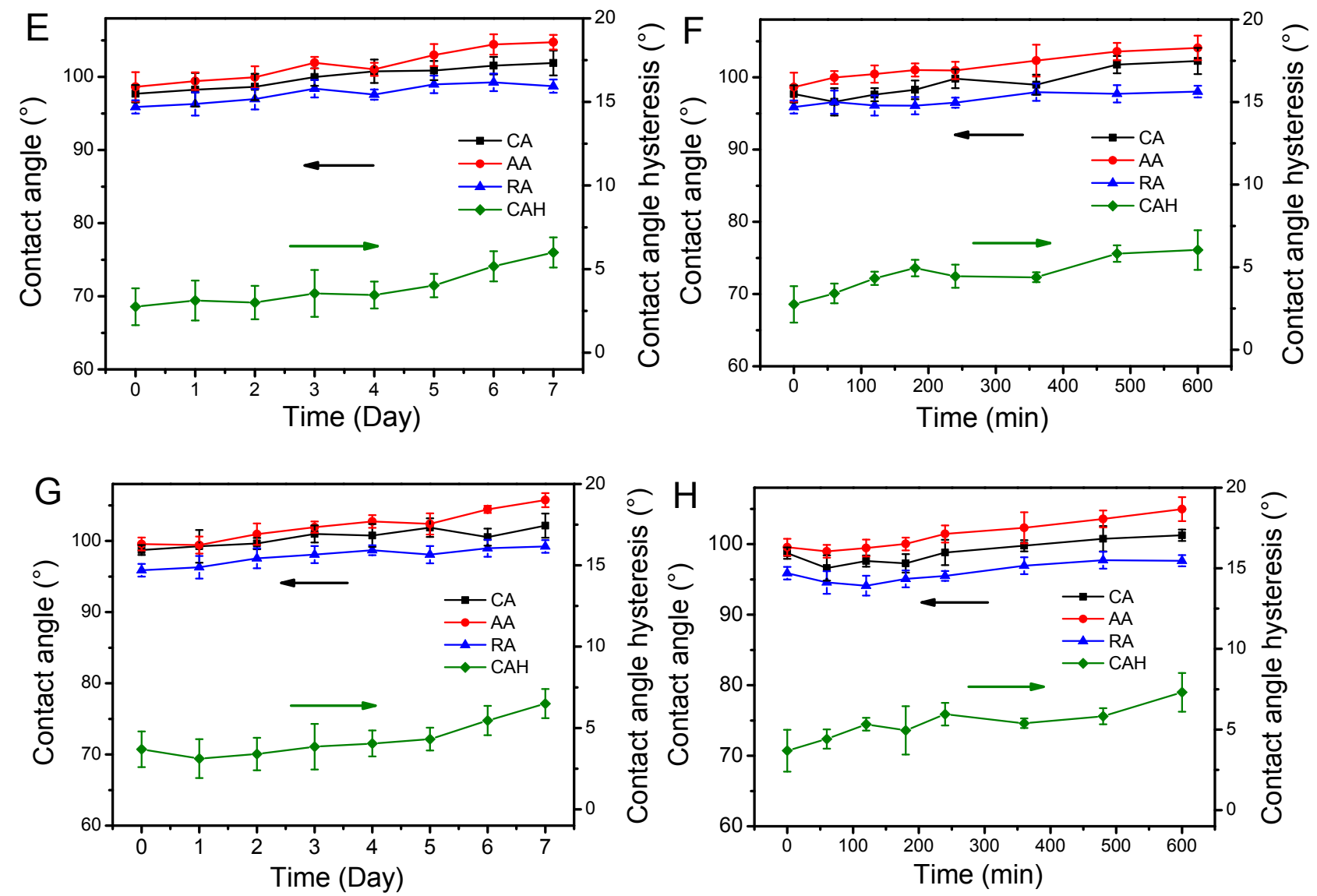

Figure S11. Variation of CA, AA, RA and CAH of PDA-mediated SLIPS formed on various substrate (A and B, PET nonwoven; $\mathrm{C}$ and D, PES microfiltration membrane; E and F, PP plastic sheets; $\mathrm{G}$ and $\mathrm{H}$, Glass slides;) after evaporation at $75^{\circ} \mathrm{C}$ for $0-7$ days (A, C, E, and $\mathrm{G}$ ) or immersion in flowing water at a stirring speed of $600 \mathrm{rpm}$ for 0-600 $\mathrm{min}(\mathrm{B}, \mathrm{D}, \mathrm{F}$, and $\mathrm{H})$. The results for SLIPS on aluminum sheets are not shown because the results are similar to those for glass slides. 


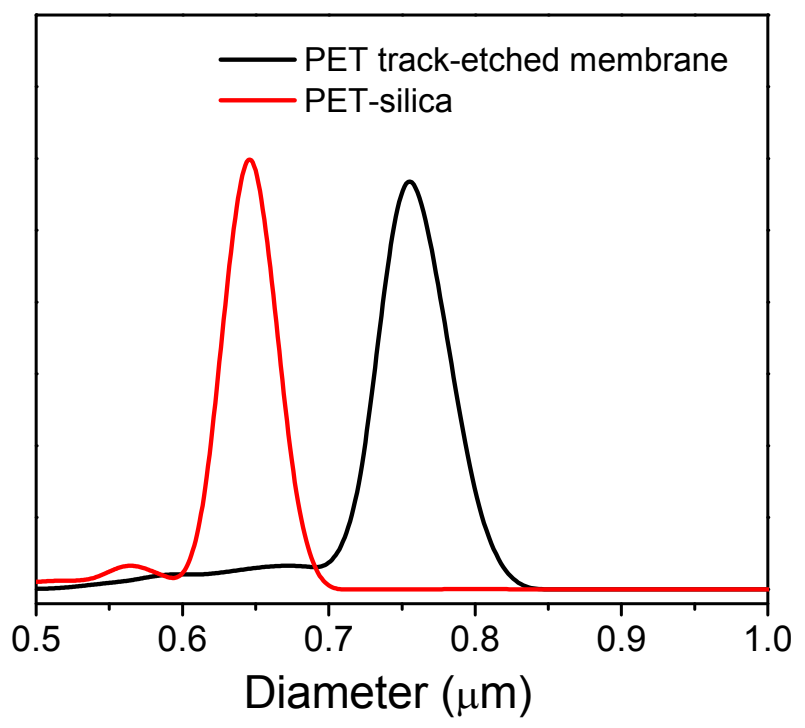

Figure S12. Pore sizes of the PET track-etched membrane before and after PDA-assisted sol-gel process measured on a capillary flow pore size analyzer (Porolux 1000, Belgium).

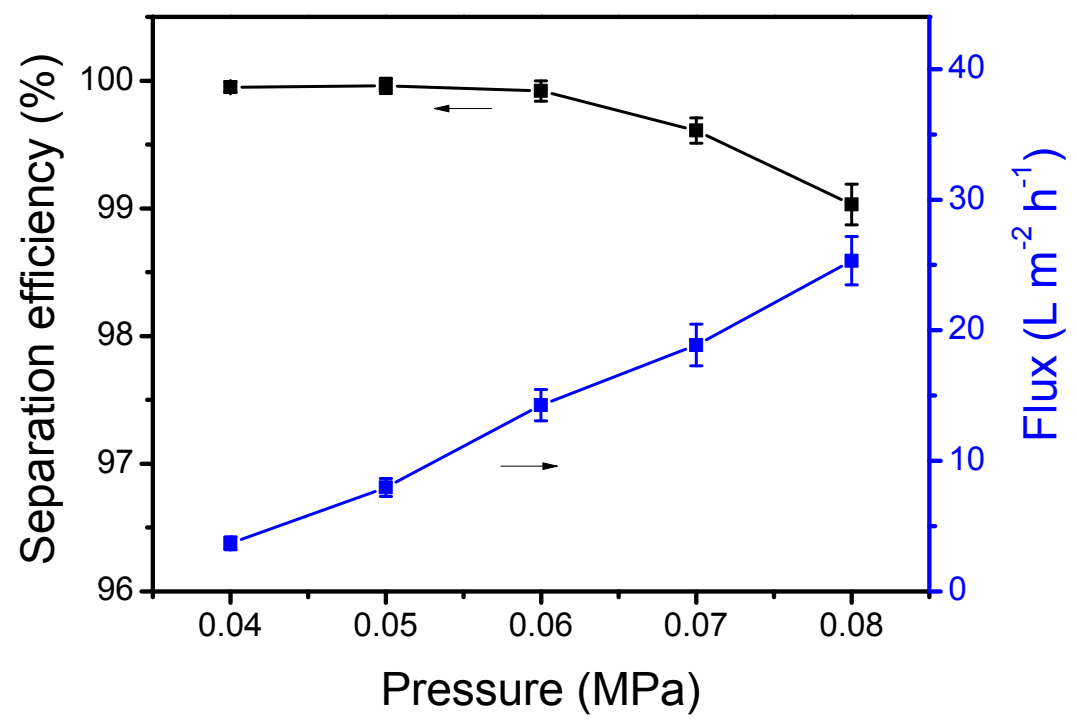

Figure S13. Separation efficiency and oil flux of PET track-etched membrane coated with SLIPS-PDA-sg for water-in-PFPE emulsion under different external pressures (PFPE was used as the lubricant for SLIPS). 